\title{
Philippe François (éd.), Anthologie protestante de la poésie française (XVIe-XIXe siècles)
}

Strasbourg, Presses universitaires de Strasbourg, 2011, 218 p.

Daniel Vidal

\section{(Q) OpenEdition}

\section{Journals}

Édition électronique

URL : http://journals.openedition.org/assr/24534

DOI : $10.4000 /$ assr. 24534

ISSN : $1777-5825$

Éditeur

Éditions de l'EHESS

Édition imprimée

Date de publication : 30 décembre 2012

Pagination : 175

ISSN : 0335-5985

Référence électronique

Daniel Vidal, «Philippe François (éd.), Anthologie protestante de la poésie française (XVIe-XIXe siècles) », Archives de sciences sociales des religions [En ligne], 160 | octobre-décembre 2012, mis en ligne le 11 mars 2013, consulté le 21 septembre 2020. URL : http://journals.openedition.org/assr/24534 ; DOI : https://doi.org/10.4000/assr.24534

Ce document a été généré automatiquement le 21 septembre 2020.

(c) Archives de sciences sociales des religions 


\section{Philippe François (éd.), Anthologie protestante de la poésie française (XVIe-XIXe siècles)}

Strasbourg, Presses universitaires de Strasbourg, 2011, 218 p.

\section{Daniel Vidal}

\section{RÉFÉRENCE}

Philippe François (éd.), Anthologie protestante de la poésie française (XVIeXIXe siècles), Strasbourg, Presses universitaires de Strasbourg, 2011, 218 p. 
1 Peut-on parler de "poésie protestante ", que qualifieraient une thématique prédominante dans les Églises de la Réforme, et une conception spécifique de l'art poétique, et du pouvoir des mots à dire la foi et l'esprit huguenots en leur singularité ? S'agit-il, plus largement, d'un regard protestant sur la poésie religieuse, comme pourrait le laisser même de l'ouvrage, qui opérerait alors des choix sur un corpus beaucoup plus différencié de textes? Le lecteur hésite à trancher. Pas plus en effet qu'il ne semble

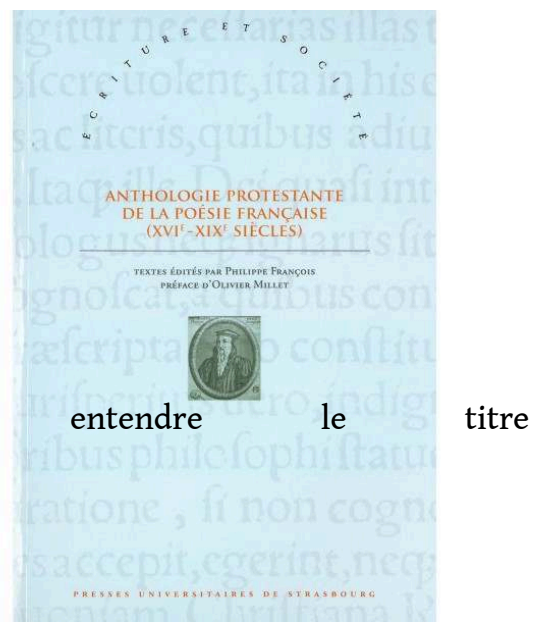
y avoir de «style » poétique propre à la Réforme, il n'est, en effet, sauf à la marge, de thématique privilégiée par le luthéranisme ou le calvinisme. Mais c'est précisément en ces «marges » que se situe Philippe François dans la présentation des poésies écrites de mains protestantes, et dans le rappel des polémiques avec les poètes se réclamant du catholicisme, ou, pour les XVIII ${ }^{\mathrm{e}}$ et XIX ${ }^{\mathrm{e}}$ siècles, tels Voltaire ou Hugo, penseurs libres et de foi non affiliée. L'un des intérêts de l'ouvrage est de présenter les textes non dans l'ordre chronologique, mais selon des thématiques globales, assez larges pour rassembler des poètes de notoriété très diverse, et d'époques différentes. De la poésie «biblique » à la grande lamentation des temps de guerre de religion, de la poésie liturgique à la méditation poétique sur les fins individuelle et cosmique, quatre siècles de rimes et de rythmes se proposent.

2 Les Réformateurs, soucieux de fonder liturgie et doctrine en langue vernaculaire, «se tournèrent tout naturellement vers la Bible», comprise comme œuvre "perpétuellement en instance d'écriture », selon la formule de Gabriel Vahanian (Dieu anonyme, 1989), et d'ouverture poétique, précise l'auteur. On connaît les Psaumes, où l'on viendra. Mais d'abord, ces poèmes sur la Création de l'Homme et du Monde, sur les grandes figures bibliques, Jacob, Jonas, et, bien entendu, Jésus-Christ. Guillaume Du Bartas, en sa Sepmaine ou Création du monde (1581-1584) et Pierre Poupo, dans sa Muse chrestienne (1590) - ouvrage trop méconnu, intégralement publié ici pour la première fois - offrent une relecture poétique de la Genèse, «jour » par «jour ", vastes fresques où Du Bartas mobilise les connaissances scientifiques de son temps en une écriture puissante et pédagogique, Poupo plus attentif à la lettre du Texte, de rythme alors moins ample. Très à l'écart de cette reprise de l'Écriture, mais magnifiant la « Puissance du Créateur », les Sonnets chrestiens sur divers sujets de Laurent Drelincourt (1677), sont hymnes à Dieu, et de grand souffle poétique. Que l'on retrouve dans ses sonnets sur les dernières heures du Christ et sa résurrection, pures lamentations mais hors de tout dolorisme, poèmes simplement de seule tristesse et pitié.

3 Les Psaumes constituent sans doute, dans l'Écriture sainte, l'ensemble poétique par excellence. Calvin initia leur traduction versifiée, réalisée par clément Marot (quarante traductions, années 1530 et suiv.) et Théodore de Bèze (cent une traductions, ca. 1551). À l'évidence, Marot n'apparaît pas cet « habile et charmant versificateur » que Gide n'appréciait guère, mais bien ce poète en consonance avec la profondeur des cantiques de David, et leur musique. Si Calvin versifie à son tour, c'est toujours, semble-t-il, selon 
une rhétorique plus contrainte, loin de la liberté du chant d'origine. De ce point de vue, Bèze, d'écriture plus subtile, annonce des traductions à venir, dont celles de Valentin Conrart, que les Réformés aujourd'hui, « cerfs altérés ", chantent encore. Dans ce même exercice, Agrippa d'Aubigné demeure fidèle à son verbe de violence désenchantée, qui s'épanouit dans ses Tragiques.

Les $\mathrm{XVI}^{\mathrm{e}}$ et $\mathrm{XVII}^{\mathrm{e}}$ siècles furent temps où la Réforme se fonda, et temps de guerres en chaîne. La poésie "protestante» salua cette fondation, et déplora ces malheurs multipliés. Tout de sensibilité, le sonnet d'Antoine de Chandieu sur la mort de Calvin, retiendra l'attention du lecteur. Contre la Réforme, contre Genève et ses rigueurs, la polémique gagne la poésie. Ronsard, Du Bellay, Malherbe usent de leurs talents pour dénoncer l'hérésie, cette peste. Ronsard : "Je n'aime point ces mots qui finissent en os / Ces Gots, ces Austrogots, Visgots \& Huguenots». Mais revisiter l'histoire de la Réforme, dire les tourments du temps, seul à vrai dire, Agrippa d'Aubigné le pouvait. Les Tragiques (1616-1630) forment cet acte implacable d'accusation, et cette longue dérive vers la plus noire des solitudes. On aurait aimé que soient publiés plus que quelques extraits en cette "anthologie » de la poésie, qui minore à l'excès ce poète majeur. Mais sa "prière et confession » (1630), sur un registre très différent du poème épique, témoigne d'un apaisement de tournure mystique, loin des fureurs du siècle. Proches également d'une quête mystique, la prière de Simon Goulart, "Lorsque la brune nuict charge sa robbe noire... » (1574) ou celle de Jean de la Gessée, «Puis qu'il t'a pleu, Seigneur, que je nasquisse au monde...» (1583): une spiritualité singulière naîtrait-elle des blessures d'une histoire à vif ?

5 Si Jean de Sponde fut, ainsi que le souligne Ph. François, « le grand auteur sur la mort », d'Aubigné fut celui qui eut «le compagnonnage le plus étroit » avec cette thématique prophético-apocalyptique. Les fins dernières sollicitent en effet une poétique qui laisse peu de place à la résignation, et magnifie la dignité dans la mort ou/et l'accomplissement du jugement divin. En effet, le protestantisme n'a pas «avivé les angoisses relatives à la mort ", et les poètes Réformés ne sont pas en déploration. Pessimiste, sans doute d'Aubigné l'est-il, ayant vision d'enfer à l'image de celui qu'il vécut en sa chair et son expérience "politique »: "Criez aprés l'enfer, de l'enfer il ne sort/Que l'éternelle soif de l'impossible mort ». Dans les dernières décennies du XVII siècle, Jean de Labadie livre des allégories précieuses, dans tous les sens du terme, concernant l'apparition de Dieu au prophète Daniel. Si elle se situe à distance de l'auteur des Tragiques, la poésie de Labadie, qui fut jésuite avant sa conversion au calvinisme, ne mérite pas le jugement dépréciatif de T. J. Saxby ("vers de mirliton ", The quest for the New Jerusalem, Jean de Labadie end the labadists, 1610-1744, 1987). Ses Saintes décades de quatrains de piété chrestienne $(1658,1671)$, ses Poésies sacrées de l'amour divin (1680), s'inscrivent dans une expérience mystique qui relèverait de l'hypothèse d'une spiritualité protestante à (re)découvrir.

6 Cette anthologie, on l'a dit, si elle obéit à l'intention première - un choix d'œuvres poétiques ayant rapport à la Réforme, son histoire, ses insoumissions (guerres de religion, insurrection camisarde), ses tragédies, ses thèmes de prédilection - semble parfois s'égarer dans la convocation de poèmes n'ayant que de très lointains rapports avec l'objet de l'ouvrage. Si l'on accepte bien sûr la place accordée à Napoléon Peyrat, et plus encore celle qui revient de droit à la poétesse inspirée du xix ${ }^{e}$ siècle, Louisa Siéfert, de même que les dénonciations par Voltaire en son Henriade des tueries de la Saint-Barthélémy, plus incongrue parait la référence à quelques vers de Baudelaire sur 
Rembrandt, de Verlaine sur Londres, ou à Moréas, comme " curiosité 'fin de siècle' »... Détails, sans doute, où ne se loge pas le diable, mais qui témoignent d'une hésitation quant à la relation entre Réforme et poésie, et l'univers d'écriture où elle s'inscrit. 